\title{
SEXUALITY: READING THROUGH AGONY COLUMNS
}

\section{Wijit Wongwareethip 1}

\section{Introduction}

It is notable that so far there has hardly been any work focusing on sexuality in Thailand, especially from Thai scholars who are working for women and call themselves feminists. On the contrary, their work is journeying over the issues of gender equity and women's oppression or other issues relating to women's bodies; for example, rape, abortion, or physical abuse. Anyhow, the above-mentioned areas of study are built only around the bodily context while the crucial key problems are not touched. As a result, their work is more or less a labyrinth in the sense that there is no way out for subverting unbalanced power relations prevailing in society. To me, a study of these key problems-a particular mode of behaviors which are tied to morality, sexuality which is conducted under the administration of power, and misconceptions on sexuality is a significant strategy to subvert power domination between different genders ${ }^{2}$.

1 Researcher at Thailand Development Research Institute Foundation, Bangkok, Thailand

2 The power relations between genders in this context does not mean only power relations between women and men, but it also includes the power struggle between heterosexuals and "the Other" (i.e. homosexuals, bisexuals, hermaphrodites, or even the disabled).
Feminists' mission, therefore, is in the broader terrain, not only the oppression of women or the bodily context, but the oppression of sexuality. To subvert this, it is important for feminists to understand that sexuality has three interlocking dimensions: sexual behavior, sexual desire, and sexual pleasure. Such oppression is an effect of the cultural and social construction of Reality 3 by power: reality about certain behaviors, desire and pleasure that reinforce heterosexual ideology. Feminists' task then is to challenge not only the social construction of sexuality, but also the sexual construction of Reality in society (Connell, 1995: 387).

Some works claiming that they are dealing with sexuality are, unfortunately, largely an exploration of people's attitude towards sexuality. Their researched objects are often groups which the researchers can easily access such as students or industrial workers. Moreover, their research

3 This cultural construction is in the process of repetitively reproducing in a vast range of social institutions such as law, education, media, morality, state and religion. Through an iterable representation or "a sedimented iterability" (Butler, 1995: 134), power can totally structure a certain knowledge, perceptions, and social relations knitted around sexuality and impose them upon the whole society as a representative of a Reality and an origin. 
methodology focuses mainly on sexual practices and what contraception the research objects use.

In this paper, I see sexuality differently from the conventional research on sexuality; it is a space hiding numerable social "codes" which create many sets of binary oppositions, exclude "the Other", and privilege certain sexual subjects. It is hence a field of conflict where varied sexual subjects compete to give a definition of sexuality. Nevertheless, this space has been dominated by hegemonic heterosexual norms (monogamy or patriarchy), norms that deny the pleasure and desire of "the Other" and that is always theorized within phallocentric language, i.e. the theory that the vagina is the "home" for the male penis. Viewing sexuality in this fashion is an initial step to disrupt the hegemonic discourse on sexuality. To study sexuality by prioritizing individual pleasure and desire, I relocate my analyzing base from phallocentrism- the way of thought whose its center is on the phallus-to "autoeroticism" (Irigaray, 1997: 323-4). By doing so, each subject's sexuality regardless of gender, class, or race will be theorized as having a different eroticism and perceptions of sexual pleasure, desire and different sexual practices. They will no longer be considered as perverts by the hegemonic discourse. The theorization as such will help all sexual subjects to have more choices and be able to control their own bodies, emotions and sexuality. All subjects will see themselves in history.

Another point that interests me here is how the Thai middle class perceive sexuality, and how they deal with other aspects of sexuality-pleasure and desire.
This paper is a small attempt to work on the sexuality of the Thai middle class. The methodology employed in this paper is an analysis of an "agony aunt" or "agony column"- a form of column in the print media where readers write letters to consult the columnist who is called "aunt." First of all, why such a column becomes a way of solving problems in relation to sexuality will be explained. Power relations and gender dynamism in the agony column will be analyzed from a gender perspective. After that, three main problems found in three agony pages ${ }^{4}$ will be articulated.

\section{Agony page: public space and personal problems}

As a column in print media, at first glance we may see the agony aunt as a public stage where anybody can come across topics on sexuality. Anybody can write a letter to its columnist or aunt, and any stranger, as readers of the media, no matter who they are, can read the stories published in the column. While reading the stories in the agony column, different reactions take place among different groups of readers. They may sympathize, adopt as their own lesson, or laugh at the way the letter writer copes with his/her problem. We can say that there is no privacy in this column, but it is public space into which everyone can "intrude"

4 These are Nares Naropakorn's Sao Aei Ja Bok Hai published in Siam Rat daily newspaper in 1972-3; Sasivimol Top Panha, of a columnist whose pseudonym is "Sasivimol", published in Lalana women's magazine in 1976; and Laew Rao Koh Pruksa Kan, of "Rangrong", published in Praew women's magazine around 1988. These are columns targeting the middle class. 
upon your private space through reading the narrative in your letter.

If your own stories are too open and expose you to the risk of being insulted or laughed at, why are there still so many people airing their problems in the agony column?

My argument is that this column has a twofold benefit to the letter writers themselves. Apart from various perspectives, advice, comfort or reprimands they receive from the aunt, this public space is in fact the domain in which the letter writers are also able to maintain their privacy. They keep such privacy through their use of "the author's name" or a pseudonym.

Generally, one of the advantages of mass media such as radio and print media is that on the basis of public space, they also provide their audience, as individual figures, privacy. Both of these medias do not communicate with their audience directly. The audience does not need to show themselves to the program producers or columnists. Radio program producers contact their audience through conversations on the telephone, and print media through writing. As such, the participant's privacy is maintained. Some radio programs or print media are so effective that they create "imagined communities" for their fans; for instance, Chumchon Jor Sor Roi is the community emerging from one radio program whose audience call in to report on traffic conditions, or Chumchon Cheva-chit is the community for those who follow Dr.Sathit Indra-Khamhaeng's concept of alternative health and alternative medicine (Komart, 1999).
In the case of the agony aunt, the private space of the letter writers is maintained not only due to the writing, but also the use of a pseudonym, or in Foucault's terms, "the use of the author's name". It is the process of naming which is political and gives a certain authority to the user as well. By the selection of a particular author's name, the letter writers can control the image or identity they want; for example, in the three texts of this study there are many authors' names implying each writer's feeling, desire or grief at the moment such as 'confused', 'desire to be a man', 'the middle child', 'a suffer chair', or the use of the word 'minor' for mia noi or the woman who is the second wife of her husband. It is clear that the author's name may not simply be either a subject or an object, or be replaced by any pronoun. Instead, it has certain functions and characterizes a certain discourse directly to those with whom the user communicates. The writing of "the author", therefore, must be read in a certain mode and "must receive a certain status" in a given culture (Foucault, 1984b: 107). The authority of the letter writers is the result of the capability to direct the columnists' and other readers' ideas towards their stories and image. Furthermore, their actual identity remains secret since other readers cannot recognize them from their voice, their handwriting, or photograph. They thus feel free to write anything they want in consulting the columnist.

Why do the letter writers dare to convey their personal problems to the columnist and other readers of the column, who are strangers, instead of to persons with whom they are intimate? What characteristics of the column and the columnists create trust 
in the letter writers? There are two issues to analyze here: the columnist as a stranger, and the nature of the column.

Firstly, the letter writers may be able to trust the stranger more than their close relations such as their parents, teachers, friends, or boss. In sexual matters, these persons may not always be those they dare to consult as it might be too risky with regards to their social status. Particularly, if their problem is sensitive with respect to social norms or morality such as the case of sex outside marriage, their fear of social censure causes them to seek another more reliable source of help. We can see that sometimes intimacy does not accompany trust in matters relating to sexuality. Because of the distance between both parties and because they do not directly communicate with each other, to some extent the columnist is deemed more trust worthy. Mostly, the columnist is considered by readers as mature, well educated and warm. In sum, communicating in this fashion writing and pseudonym use can keep a private space and authority due to some distance between both parties. Likewise, this distance impacts on feelings of trust towards the columnists. For all these reasons, many decide to write letters to the columnists on the agony page.

Secondly, trust in the column derives from the familiarity that letter writers have with the agony column they frequently read. As the column's fans, they will finally know the column's "geography." This is to know its standpoint, style, and policy. By knowing this, the letter writers will know the scope of problems they can consult the aunt about in this space. Different agony columns in different print media have different "geography." The letter writers need to know which agony column they can consult for particular matters.

We have to understand that the pattern of the agony page is a result of media policy, which affects the publication's way of representing, selecting, editing and agenda setting. It is even possible that not every letter is paid attention to and read carefully. Why are some letters not published? Is it because the "problems" in these letters were so pernicious? The point is that this selective process is not the sole action of the columnist (or aunt) as such. Rather, it is mediated by the policy of the media, social norms and particularly the perceived reaction or satisfaction of the readers. And even the media's policy has to rely in part on the expectation of the readers, social morality and social norms. Columnists or publishers, thus, are unable to exercise total control over the content and layout of the page without consulting or studying what their customers and society expect. This can be seen in the agony columns which have no specific columnist or aunt, but the selective process is still going on. It is interesting to analyze why such agony columns (that seemingly do not have an aunt but just a space for different emotional stories) become popular among readers. This popularity derives from the role of an "imagined community" among the readers and letter writers; the community that opens the space for their suffering and shares their cruel lives with others within a rapidly changing society. The stories and demons of people's lives become a shared emotion among the community's members. Touching this suffering is touching the community's "nerve". The nerve of the community is therefore 
the conductor of the story telling, and suffering, in the column. In this sense, one could hardly draw a distinction in the triangle between letter writers, aunt/ editor/publisher, and the readers. This triangle does in turn affect the social perception and expectation on sexuality.

The letter writers put their trust in the column because they know its nerve very well. They know what the main discourses in this domain are. This also means they know what they can or cannot write, and what style of writing or scope of topic they need to conform to. Being accustomed to the geography of the column, the letter writers feel free to express their sexual problems on the agony page.

\section{Thai middle class and power relations among different genders on the agony page}

One interesting question is why most letter writers to agony aunts are female, and what is gender dynamism here? To answer this, there are three points to consider here; namely, the middle class, sexuality, and gender of those who are involved in the column (columnist and letter writers). The middle class in this paper is framed to mean those who are educated, at the middle or even high rank in their working place, and whose age is under 50. They believe in humanism and rationalism (Nidhi, 1995: 242-52) any success they have gained is the result of their own "doing", either educational background or working experience.

In the Thai context, the middle class consists of people between the high class and the common people and rural people.
They are those who are most sensitive to global changes, and they are enthusiastic information consumers. Compared to other groups, they are more flexible in the sense that they are not so attached to particular social values. Furthermore, their historical origin makes them very individualistic. The majority of the Thai middle class in urban centers, especially Bangkok, is the product of industrial development. This development entailed enormous changes in Thai society; namely, land reform, the mass exodus of rural people moving to working sources which are dense in town, and unbalanced development. This first generated the lower middle class in the city, from which some of them finally attained higher social status due to their increasing "purchasing power". After entering the city, factors such as limited space and hardship in the larger world make these people unable to gather together in the same pattern as in their conventional community. Also, they are too busy or are simply disinclined to make new friends with people living nearby. They then live among "strangers." Besides, the housing construction business has created a new type of "village" (Nidhi, 1992: 40). It is not the village which has collective memory among community residents. It is the village categorized by purchasing power. Those who have greater purchasing power, live in exclusive villages, whereas those who have less live in simple villages. The village per se is not the place where people gather naturally, where everyone in the community is more or less related, either through work, psychological community, or through a dependence on other figures in the village in some sense. Instead, many strangers as newcomers live in the same village on the grounds of their 
similar level of purchasing power. New housing construction design aimed at practicalities, closeness and privacy may be suitable to the size of the Thai middle class family, which is becoming smaller. The lifestyle of the Thai middle class is packed and available for buying. All these are the causes that separate people from their previous traditional community, and the "villagers" do not need to deal with each other too much. They, therefore, strongly believe and act in an individualistic way. In summary, a new definition of the village is that it does not depend much on the power of clientelism and communitarianism to regulate itself, but needs more contractarianism or formal relationships under certain literal contracts. 5

Other than purchasing power, the Thai middle class also gives importance to reason and believes in their own "doing", which can be called humanism. The members of this class no longer rely on fortunetellers or the supernatural to solve personal problems, especially those associated with sexuality. (Nidhi, 1995: $252-5,322$ ). Moreover, there are four reasons why the middle class turns to consult agony aunts when they are facing sexuality problems.

First of all, while respecting each other's privacy, the middle class also regards each personal problem as an individual's

5 See a critical remark on three modes of power relationship existing in Thai society from Kasern Tehchapeera, 1999., "The Mode of Thai Power: Power Relations in Thailand Health System" in Nipon Paopongsakorn (ed.) The Contributions in Honour of 60 Years Ammar Siamwalla, Bangkok: Jootthong. (in Thai) private concern. They are not sure whether their concern may be viewed as an invasion of someone's privacy. The meaning of public and private sphere has changed and become more complicated. Private matters can be published in the public sphere on the condition that they retain some privacy. Secondly, since there is no close relationship of community among the middle class, there is also no community leader in whom the "villagers" can put their trust, or to consult on these matters. Thirdly, there are many new categories of professionals, generating "experts" in each sub-field. As noted above, people who have sexual problems seek the person who has a particular distance and at the same time has less expectation towards them. Lastly, while nowadays it becomes more and more difficult to find any person willing to listen to one's problems, the agony page is the space where one is able to find the person who can either give him/her empathy or agree with the justification in their story. The agony aunt, hence, is the best option for responding to the everyday concerns of the middle class.

Within the middle class, are there any differences between women's and men's status? Although the middle class believes in humanism and rationalism which espouse equal treatment for women and men, in gender relations and in the matter of sexuality, women know less than men. In Thailand, boys and men have more chances to discuss, practise and explore their sexual desire. Through language, it is acceptable and common for boys and men to boast about their experiences or "knowledge" about sex, unlike girls and women whose morality and social expectations confine them from free 
expression of their feeling or action regarding sexuality 6 . This implies that Thai society gives different rights of expression to men and women.

As mentioned above, since the members of the middle class are generally educated, the problems written to the agony page are not simply basic or general problems on bodily matters, sexual organs or naivety on sexual activities. Furthermore, as their meaning of sexuality is not reduced to only the sexual act, but includes sexual desire, sexual pleasure and emotion as well, most problems they write to the columnists about concern conflicts between desire and pleasure and socially constructed norms. Such conflicts are the result of a particular socio-cultural production that sees kamarom (passion) as

6 This is one controversial topic needed to be discussed further. Many said that the limit of women's sexual expression is to control their sexuality which is used to be an indicator for measuring society's overall morality. Consequently, women have to admit the "forced identity" society put into them. On the other hand, there are another argument disagreeing with the former. They do not think that women are passive objects to be oppressed by any discipline. By contrast, they views that some women are willing to take such discipline to fulfil their desire. This is why some women can bear all the pain and cost just to make them feel good about their looking, or be a properly feminine body. Parts of the reasons behind this pain toleration are as follows: it is to make them become fashionable, to subvert certain traditional values, or it is "a rite of passage into adulthood, the adoption and celebration of a particular aesthetic, a way of announcing one's economic level and social status, a way to triumph over other women in the competition for men or jobs, or an opportunity for massive narcissistic indulgence" (Bartky, 1998: 37). disgusting and that honors virginity and monogamy as the highest values of women. This is the cultural production which was constructed to control the pattern of sexuality in the Early Bangkok period (roughly between 1782-1851). The Thai middle class inherited such culture from the Thai elite of that period. Yet such culture, in the forms of literature, worldview, and behavior patterns, is viewed by one historian as wattanatham datcharit because it is a culture which is not relevant to the sexuality that really exists in Thai society (Nidhi, ibid.: 269). In fact, sexuality for Thai people is neutral, not good or bad, as we can see that they can joke about sexual matters in many places (see more explanation in the next section).

Therefore, this pattern of Thai Culture is culturally constructed, partly influenced by Victorian society which the Siamese elite and kra dum pii adopted since the Early Bangkok Period. The main point is that the Victorian culture represents puritan values that claim sexuality is entirely a personal matter. Women and those deviants are the main target groups that the Victorian society sought to control and dominate. Women are not allowed to express their desire. The less women know about sex, the more they are considered as "good women", whereas the more men know, the more they are considered in a positive way as knowledgeable and experienced.

In the three agony pages I considered, most -letter writers are female of diverse generations while there are few male letter writers. Does this picture imply that women have more problems regarding 
sexuality than men? What does gender dynamism in this space look like?

To answer these questions, first we have to reconsider the meaning of sex. Sex, as it is generally understood, is an attribute in accordance with physical appearance and the genital organs. A person must have only one sex in oneself, either man or woman. From this biological attribute, the person will be socialized to have a certain sex role according to what society expects him or her to be. Men are conditioned to have different social expectations from women. Such social expectations are the outcome of the constructed culture noted above. It determines the code for proper behavior, womanhood and manhood.

Under the discourse of traditional Thai culture, women were repressed by the use and manipulation of morality. Not only must women not have any desire or derive any pleasure from sex, but they must also not have knowledge on the issue. Otherwise, they are seen as immoral and bad women. By contrast, men have a more privileged standpoint in this matter. Though this is not obvious, men are supposed to have an insight into this privilege.

The gender dynamism on the agony page can be considered from two perspectives: that of the letter writers and that of the columnist(s). And age seems to be another important factor for this dynamism.

From the first perspective, it is interesting to analyze why most of the letter writers are women of various generations whereas only a few males wrote to the column. In these, it is males who are either in their upper 40 s or in their early 20 s. The former group of men writes to the column as adults advising, correcting, or guiding "kids" along the proper path. They do not write for any consultation, but write to confirm their shared values with the columnist. In contrast, the latter group of men, who are very rare in the column, writes to the column for two reasons. Firstly, they are often confused about their sexual status. Secondly, they, as (biological) men, do not know their "advantageous position" in the sphere of gender politics. "Advantageous position" means the privilege in society of which men have more than women. If they do not know or know less, they may be treated as women and be taken advantage of by the men who are "macho." These men are seen as being "socially women" (Thanet, 1987). From these, the term woman needs to be rethought, as it does not merely mean a person who has female genitals. Rather, "woman" now is a signifier meaning something opposite to other categories such as "maleness." 7

Unlike the above picture, women in every age group write to the agony page. This is not because they have more problems regarding sexuality than men, or because men have more solutions. My argument is that in the area of sexuality, men are expected to understand or be knowledgeable in this matter. Or we can say that they are those who produce and institutionalize the discourse on sexuality. They are the owners of such discourse; therefore, they do not need any consultation on this matter. If they do, it is really a kind of embarrassment, and they

7 Editor's introduction of Teresa de Lauretis's article. See Teresa de Lauristis, 1993, "Upping the Anti [sic] in Feminist Theory," in: Simon During (ed.) The Cultural Studies Reader, Routledge: London and New York, pp. 74-89. 
are probably being treated as "socially women." In contrast, it is women, who have been repressed from the so-called Thai culture, and some who are "socially women" who need consultations from the page. It is hence not surprising that most aunts in the column are male. Other factors such as age, nationality, or sexual preference are not obstacles to taking this duty (i.e.Todd Thongdee, Saeree Wongmonta). In addition to being knowledgeable and standing at an advantageous geographical position, men are freer to talk about sexual matters than women. Female aunts, are able to discuss this issue without any backlash from society in cases where they meet particular qualifications; for instance, high education, maturity, or are highly respectable (i.e. Chintana Yossuntorn, Somsri Sukumolnan, Kritsana Asokesin). Only women who have these qualifications are "allowed" to be aunts.

From the above-mentioned statement, we can see that power relations in the agony column are very complicated. Apart from the gender and age of both letter writers and columnists, social expectations in the terrain of sexuality also determine when and how sexual matters can be voiced under the limited frame of the so-called Thai Culture.

Virginity: good woman, purity, and decency

In the agony column I have analyzed, there are two extremes in issues relating to sexuality. One is the notion that being the "good woman" is measured in accordance with her marital status. Before marriage, a woman's highest value is being a virgin, while after marriage her value is being a good wife and good mother. This differs from another notion which tries to show that women's lives are multi-dimensional. As such, a woman's value rests not on her hymen or on being obedient to what social norms may impose on her after marriage. Rather, her value is a result of her deeds and her work.

The first conception is apparent in Nares' text, Soa Aei Ja Bok Hai. Seeing that virginity is the highest value a woman may have and viewing that all women are very ignorant in sexual matters, what Nares did in his writing is to provide all female reader a "knowledge." It is knowledge aimed at protecting women from a vicious circle of "bad" sexual behavior; for example, pre-marital sexual intercourse, oral sex, anal sex, and homosexuality. Particularly, he stressed "knowledge" of the dangers which are risky to a woman's virginity. Nares notes that having pre-marital sex is a precocious sexual relationship and this often makes women disadvantaged in relation to men. As a result, both the time (chance) and place that such a sexual encounter may take place is elaborated in detail to warn his female readers. For instance, the chance of staying together with a man out of public sight, the risk of driving alone at night, or "dangerous" places such as motels, hotels, dormitories, rented houses, the cinema, photo shops and on the bus.

However, there is a contradiction between the role of women before and after marriage. Before marriage, women are told to be alert, strong-willed and not to allow any man, not even in the case that the man is their fiance or their beloved, to take advantage of them. And if the man deceives or forces them, women have to 
protect themselves actively and aggressively even though their selfprotection may hurt the man. After marriage, counting from the first night, on the other hand, women are told by the author to be passive and "let it be the bridegroom's business" (Nares, 1973, vol.1: 112-4; vol.2: 78).

However, Rangrong, a full time historian and university lecturer, views the relationship between women and sexuality differently. He finds that the Thai middle class's attitude, including Nares's attitude, towards gender relations and sexuality is cultural. This means that it is constructed through the process of constant and repeated reproduction manipulated by the powerful. Such a category of constructed culture is wattanatham datcharit; namely, it is not relevant to the sexuality that really exists in Thai society. People in the past and even contemporary rural people do not regard sexuality as dirty and obscene, but they have a healthy and sanitary attitude towards sexuality. This can be seen from sexual code represented widely in folk music, mural paintings, poems, or even the bun bang fai ritual, et cetera, as a commonplace and funny thing (Rangrong, 1988: 110-1). He therefore tries to deessentialize/unmask wattanatham datcharit regarding sexuality. Indeed, sexuality in itself is a neutral issue, but we discern it as right or wrong because we have been gradually socialized by certain values. Rangrong posits that this is produced along with the notions of gender and the nuptial institution. For instance, virginity is considered as the highest value for unmarried women. It is made to have the same meaning as cleanliness, purity and beauty. And if these women lose their "purity" before having a formal wedding, they will be regarded by society as loose women.

The discourse on sexuality is not just simply constructed in this manner. It is a highly sophisticated process by which single women, who are not virgins, are made to feel valueless, label themselves as sinners, and have no self-respect or selfconfidence to start a new life with another man. Furthermore, they have to be loyal to the man who "got" them as the man is their de facto husband, and therefore they should not have other men. Otherwise, they are regarded as promiscuous. In other words, the principle of "first husband/one husband" aims at maintaining the sacred rule of monogamy: the unbreakable rule responsible for upholding the decency of society. Rangrong sees this as the most negative effect of the socialization that teaches women to celebrate their virginity as the very value of womanhood. Such teaching pushes the women who lost their virginity outside the nuptial institution deeper into a self-contempt from which they are unable to recuperate (ibid.: 51 ) in spite of the fact that women's value is more than the tissue in her vagina. On the same ground, a wife is the woman who shares a husband's happiness and grief and who is an equal economic, social, and political partner (ibid.: 96). Moreover, a husband is not simply the man who sleeps with a woman, but his role is broader and more profound than that (ibid: 29).

In Rangrong's opinion, women's virginity is supported by a teaching about nuan The different underlying reasons justifying the practice of rak nuan sa-nguan tua, or chastity, are also articulated in other academic works of Rangrong. He argues that there are teachings referring to the 
practice of pre-marital sex; i.e. a notion of pid pii (doing wrong against ancestors). At any rate, the Thai cultural value of pid pii is not to solely protect against pre-marital sex, but its main objective is to have an appropriate ritual wedding after such sexual practice (Nidhi, 1998: 46). This differs from Victorian ethics. Good women by Victorian standards should be naive, innocent, and chaste and have no passion at all, thereby opening more space for men to experience and explore the world, including sexuality. In sum, chastity and naivety in sexual matters in Victorian culture are equal to purity and decency. Women are excluded from the very realm of sexuality, which simultaneously excluded women from any knowledge, desire and pleasure as well.

On the contrary, women's chastity from the perspective of Thai culture is an attempt of the kra dum pii of the Early Bangkok Period to limit women's freedom, which was better in comparison to women in feudal times. A good wife in kra dum pii culture was not of the same pattern as under feudalism where women were supposed to be obedient and "docile" as illustrated in real feudal literature, such as Kritsana sorn nong (Lady Kritsana teaches her younger sister). Increasingly participating in family business, kra dum pii women obtained more freedom than women in feudal times. Such freedom included freedom in matchmaking and sexuality. As the French Catholic Bishop Pallegoix, who visited Siam at the time, reported it was common for women to follow their lover (ibid.: 186). Yet, for kra dum pii, marriage involves economic and political interests, and their individual desire may sometimes invite conflicts with their class interests.
Its literature-Supasit sorn ying (poem for teaching women), hence, aimed to teach single women to rak nuan sa-nguan tua, and to consider economic factors in the process of choosing their husband.

\section{Polygamy and women's oppression}

"The habit was Oriental"

King Mongkut responded to foreigners' attack on the Thai elite's practice of polygamy

(Bowring, 1969: 411; cited in Reynolds, 1977: 940)

Most of the knowledge we have about Thai sexuality comes largely from the knowledge of how women are expected to behave in a "proper" way. Such expectations operate through many forms of explanations, through belief 8 , historiography and literature. These are formal versions of knowledge about sexuality.

One major source of knowledge to which those who are interested in Thai sexuality and gender relations always refer are historical documents, especially Thai traditional law, such as Kot mai tra sam duang or Code of the Three Seals Law. In this, married women were categorized into

8 An anthropological study of Trok-Tai Slum in 1968-9 reports that an unequal relationship between women and men in this community bases on religion belief. For instance, once the researcher assisted a woman collecting her clothes. She was so shocked and asked him to stop. It is sinful, she explained. Women can collect men's clothes or men's other belongings, but certainly not vice versa (Akin Rabibhadana, 1980: 81). 
three "classes": a) mia klang muang9; b) mia klang nok ${ }^{10}$; and c) mia klang thasi. ${ }^{11}$

Sometimes a noble was given a wife by the king as a reward. The status of this type of wife was superior to those mentioned above (Amara, 1997: 8). By using this category, Amara Pongsapich argues that the patriarchal aspect can obviously be seen in such law, and the status of Thai women in the Ayutthaya and Early Bangkok Periods, when such law was reinforced, was worse than in earlier periods. Different types and status of married women indicate that male polygamy was widely practised, and women had to accept their subordinate status.

Is this feminist understanding of Thai sexuality correct? Although Amara employs Kot mai tra sam duang as historical proof of women's oppression in the past, Thavit Sukpanich (1988) finds that such an argument comes from a partial reading of the law. To generalize from such a partial reading and understand it as the whole purpose of the laws leads feminists to misunderstand the law. Here, there are two points researchers need to understand. First, Kot mai tra sam duang was a compilation of many trials, not a

9 It literally means wife in the middle of a town. This is the wife of a ceremonial wedding arranged by both parties.

10 Literally means wife/ves in the middle of an outside. This is a wife brought in by the husband.

11 Literally means wife/ves in the middle of slaves. This is a wife the husband bought to free from her debtor, or even free from himself if he took his former slave as his wife/ves, as she had to be free from her debt by de jure. code. Therefore, to see whether the law was fair or not, all of them must be read. Second, Thai law is based on justice which is not necessarily equal; and this is different from the Western notion that equality will automatically entail justice. Thavit also adds that the oppression of women is not relevant to the number of wives, and if the husband intends to oppress, it is not a matter of how many wives he has. Although the husband has more economic power, he is not the lord of life of his wife(ves) at all.

According to Thavit's study of Kot mai tra sam duang, women were more powerful than what feminists thought. For instance, they could initiate divorce at anytime, thus allowing women to evade an abusive husband. In practice, the selling of a wife could not take place without the wife's consent. Moreover, it is not only men who have rights, but wives also had a special status under the law. The status of a Thai wife in article 34 of Phra aiyakan luksana puo-mia (the code on husbands and wives) indicates that a wife has the status of mae chao ruan (the Lady-owner of the house) (Thavit, 1988: 88). This indirectly forces the husband to find a permanent and personal place for every wife he has no matter how large it is (article 117). He could not bring any other women to his wife's ruan (house). If man wanted to have a new wife, it would cost a lot to find a new place for her. Otherwise, he would be charged with "damaging a daughter (of others) by taking her wandering around" if he could not find a permanent place for the new wife.

To some extent, I agree with Thavit in the sense that Thai feminists do not understand the whole structure of Kot mai 
tra sam duang. Thai feminists so far have misread the law and misinterpreted women's status. Yet, we have to be aware that Thavit's argument is grounded only on what was written in the law. What really happened in the past is beyond his analysis. It is impossible for us to know how many Thai wives took this law into their consideration and came out to demand their rights. Moreover, we should not forget that Kot mai tra sam duang was in the hands of male authorities. It was a construction of a particular form of sexuality in order to "administer" and shape the relationship between women and men into a single model. What Thavit did, therefore, is to defend a "phallocentricism" by using the law to argue against feminists' argument. $\mathrm{He}$ may not have intended to do this, but he has already supported a masculine language that pleases the fantasies of men in responding to their sexuality. Thavit's argument here becomes a justification of the pattern of male polygamy in the past.

To me, both parties' discourses have a common weakness; they rest their explanation on the same thesis- the source of women's oppression is men. Indeed, we can see both direct and symbolic oppression among women. In conclusion, if other elements, such as class, age, and race, are taken into consideration together with gender oppression, the analysis will have more dimensions than a stereotype of women and men as victims and villains.

Besides, those who are working for gender equity may need to consider Thavit's comments. They should then shift the focus of their argument from the number of wives to women's own sexual desire and pleasure. To me, it is too superficial to explain that women in the past were oppressed by looking at their status as a wife among many women of her husband. Instead, it is more interesting to see it as women's politics. The women may do this intentionally. Being the wife of a man who has had many wives may be her own choice to respond to her sexual desire and pleasure. It may be the politics women choose to play and write for herself. By analyzing in this way, women are no longer "forever-victims" for feminists.

\section{"Vanthong song jai" and women's one man}

Having only one man in life seems to be the behavior of the "good girl". A woman should not like Vanthong, a figure in a well-known folktale who has two husbands. Her name has come to mean women who are fickle in their relationship with men. In the texts I have studied, one of the most popular questions written by women to the agony "aunt" is, which man should a woman choose? The reason is to avoid being dubbed "Vanthong song jai", which sounds negative to the audience. This is another interesting topic needed to analyze the cultural prison that justifies a particular pattern of women's sexuality. Why does such a pattern make women feel that their duty is to have only one man? Interestingly, there is no idiom or folklore blaming men who have two (or more) wives. Conversely, if women do, they are stigmatized. Why is male desire to have many lovers considered as less severe than female desire to do so in spite of the fact that it is more or less the same? And why does a cultural instrument like a proverb not have any words reprimanding the same behavior of men? 
Yet, to be a Vanthong does not merely mean having two husbands. Rather, its meaning is applied to call girls who have many boyfriends at the same time as well. As such, we can see that the discursive practice of "Vanthong song jai" operates so efficiently to discipline not only married women's sexuality but also single women in the process of selecting a suitable boyfriend so that they will not be called "the two-heart Vanthong".

The most crucial factor enabling the word Vanthong to have a sense of disgrace is that it works closely with two other social values: monogamy and an honor of women's virginity. Even though the 1935 Family Law was aimed at men with many wives and mistresses, this monopoly principle had instead become a sacred principle imposed solely on women. In short, whereas the Law aimed to enforce men's sexuality, it turned to be a fortress in order to administer women's sexuality at an ideological level. This is why such a proverb can still be used to control women nowadays.

Apart from expanding its meaning and scope of control over women, either married or single, in their relationship with men, the term Vanthong also has indirect impact on women when taking the honor of virginity into consideration together with monogamy. Some women may have to stay with her "first man" (i.e. the first man who took her virginity) though they are not happy with that or they do not love their "first man." This is because they want to have only one husband. For this matter, Rangrong views that "The husband is not just the man with whom you have slept." He never cares about such a superficial definition of being a husband. Rather than taking the idea of "first man/one man" as an important principle, Rangrong suggests that living with her "first man" does not guarantee her a happy life. On the other hand, seeking a virgin to be their wife does not provide men with genuine happiness. Therefore, what a couple should think over before making a decision as to who will be their life partner is each other's value, not just whether the woman is a virgin or the man is her "first man." "Looking for and building up each other's values is a precious value for a couple which, unlike the hymen, can never be destroyed" (Rangrong: 1988: 27, 97).

In summary, analyzing the letters written to an aunt, the words "Vanthong song jai" reflect the following three points. Firstly, this is a discursive practice honoring monogamy and setting the agenda successfully since the beginning process of selecting a "suitable boy." Secondly, these female letter writers pay more attention to the process of selecting a suitable boy than delving into the man's other aspects for the sake of their longlasting relationship. They think that everything will end beautifully after they have selected the suitable boy, as a girl mentioned that she will be able to tolerate every not-so-good-ness of the man whom she has carefully selected (Sasivimol, 1976: 515). This is another idea the conception of monogamy has imposed on women: loyalty and patience. Thirdly, we can say that the proverb is one of sophisticated technologies of power by which society formulated a sacred rule-a one-sided monogamy-to impose only on women. 


\section{Final remarks}

Looking at their standpoint, these male columnists, except Rangrong, seem to fall into the trap of social construction on gender relations and sexuality, or even construct a new social norms relating to sexuality. For instance, Nares has established a dichotomy of Thai/non-Thai, decency/wickedness, and morality/lust. For him, Thai culture is a decent culture differing from the western one. Thai society, Thai people, especially women, were pure and uncontaminated until the so-called "indecent farang [European par excellence the western] culture" entered Thai moral borders. Thai culture in such a "golden age", hence, is desirable, and it must be frozen. Farang or western culture is described in the text as the cause of premarital sexual relations, inappropriate dress, sexual crime, and promiscuity which later came to exist in Thai society. Nares argues, 'the Thai custom of preserving one's virginity is disappearing and melting into farang culture that discerns sexual relations as no one gets or loses' (vol.2, 141). Thus, he warns his female readers that in case any men ask them to nonn [to sleep with], it means not only that those men are insulting them, but they also demean the "high" Thai culture. Therefore, women have to reject such sexual invitations which simultaneously would be a betrayal of our beloved nation (vol.4, 53). From this perspective, the Thai nation in Nares's viewpoint is a sexually disciplined nation. Having sex becomes a national agenda.

Sasivimol also falls into the established norms when he answers a letter of a kathaey who passes "her" days uselessly, nonsensically and ridiculously (Sasivimol,
1976: 201-3). In this case, Sasivimol as "the author" has a certain definition of what constitutes a good homosexual in his mind. Therefore, rather than empathizing or encouraging "her" (because "she" is having low self-esteem), he uses his hierarchical standard of being a good gay to correct "her" for the sake of a good image of the whole gay community.

Only Rangrong is aware of such a construction. He sees all existing norms as metanarratives which exclude other alternative narratives. Throughout his texts, Laew Rao Koh Pruksa Kan, he patiently documents how "a field of knowledge" about sexuality had been entrenched in people. This is called genealogy: that is, an endeavor to reject "the metahistorical deployment of ideal significations and indefinite teleologies." As a historian, he sifts through Thai folk history which shows that "there is 'something altogether different' behind things: not a timeless and essential secret, but the secret that they have no essence or that their essence was fabricated in a piecemeal fashion from alien forms" (Foucault, 1984a: 77-79). In other words, there is no single narrative or value on sexuality. Rather, sexuality is diverse depending on desire and pleasure which simultaneously direct an individual's varied sexual practices.

From the main issues found in three agony pages, it is clear that there is a particular form of gender relations and sexuality existing in Thai society. The power limits people's choices of pleasure and desire through many devices. For example, the pattern of "good" woman in each period has framed and confined women in one fashion, and limited their choices just to 
meet social expectations. Women's pleasure and desire are less in comparison to men's. In case they do not follow the established form of gender relations and sexuality, morality, which is a great subjugation in Foucault's view as it is "ways of rendering it morally acceptable and technically useful" (Foucault, 1978: 21) will be employed to blame them or make themselves feel guilty. However, it seems to me that the same morality does not work well among men. I assume that this is because the technology of power has been operating so efficiently as to make women internalize social expectations.

Some readers may object to my presentation on the above three most popular issues found in the agony pages by arguing that these three issues are no longer problems today 12 . However, my point is not situated at how Thai men have changed their idea about women's sexuality. Instead, I am writing this paper by concentrating on why many Thai women still firmly and incessantly cling to the grand narrative on virginity and monogamy. We been lived in an academic world which allows the phallus to be a center for our analysis for too long. How and why men have changed their idea does not make these three issues become old women's problems. The main questions of this paper are how social machinery establishes women's virginity as a significant matter; and why a behavior of having many lovers has a different degree of disgust if the actors are women, not men.

12 Some said nowadays Thai men do not care much about women's virginity or they can accept if women are fickle sometimes in order to finally meet their Mr.Right.
To me, the above questions are as important as the research on sexuality focusing on prostitution and AIDS. Unfortunately, the research centering around individual pleasure and desire is very rare. This paper, therefore, hopes to go beyond such traditional research on sexuality; namely, (1) the sexuality constituted under phallocentrism, (2) the analysis limited into bodily context and sexual behavior and (3) the analysis grounded in a certain stereotype in which women are always "made" as victims.

In order to challenge the use of morality by the powerful, and to open more space for individual pleasure and desire, this paper has proposed autoeroticism as a new paradigm for studies on sexuality. As I view it, if any discourses start from morality, women and other oppressed groups will have no option except to accept the established norms of sexuality designed by the powerful. And analysis of agony pages is very useful to see how some Thai people perceive sexuality as it is many places where autoeroticism can be expressed rather freely. In the meantime, it is also a space which mirrors sexual suppression in Thai society.

\section{References:}

Aeusrivongs, Nidhi. 1984. A Quill and a Sail: Essays on Literature and History of the Early Bangkok. Bangkok: Amarin Printing. (In Thai) 1992. Bangkok: City of Cultural Diversity. Decade. Vol.2, No.13. pp.: 31-42. (In Thai) 1995 (second edition). $A$ Quill and a Sail: Essays on Literature and History of the Early Bangkok. Bangkok: Amarin Printing. (In Thai) 
Sexuality: Reading through agony columns

Aeusrivongs, Nidhi. 1998. The Culture of Poverty? Bangkok: Amarin Printing. (In Thai)

Bartky, Sandra Lee. 1998. "Foucault, Femininity, and the Modernization of Patriarchal Power" in: Rose Weitz (ed.) The Politics of Women's Bodies: Sexuality, Appearance, and Behavior. New York and Oxford: Oxford University Press, pp. 25-45.

Bowring, Sir John. 1969. The Kingdom and People of Siam with a Narrative of the Mission to that Country in 1855 ,volume 1 Kuala Lumpur: Oxford University Press.

Butler, Judith. 1995. "For a Careful Reading" in: Seyla Benhabib (et al.) Feminist Contentions:A Philosophical Exchange. New York and London: Routledge. pp.127-143.

Chengsathernsup, Komart. 1999. What does Cheva-chit phenomenon reflect Current Thai society? Bangkok: Khomolkhemthong. (in Thai)

Connell, R.W. 1995. "Democracies of Pleasure: Thoughts on the Goals of Radical Sexual Politics" in: Linda Nicholson and Steven Seidman (eds.) Social Postmodernism: Beyond Identity Politics. New York: Cambridge University Press. pp.384-397.

Foucault, Michel. 1978. The History of Sexuality vol.1: An Introduction. London: Penguin Books. . 1984a. "Nietzsche, Genealogy, History" in: Paul Rabinow (ed.) The Foucault Reader. London: Penguin Books. pp.76-100. 1984b. "What Is an Author?" in: Paul Rabinow (ed.) The Foucault Reader. London: Penguin Books. pp.101-120.

Irigaray, Luce. 1997. "This Sex Which is Not One" Translated from "Ce sexe qui n'en est pas un" (Paris: Edition de Minuit, 1977) by Claudia Reeder. in: Linda Nicholson (ed.) The Second Wave: A Reader in Feminist Theory. New York and London: Routledge. pp.323-329.

Naropakorn, Nares. 1973. Sao Aei Ja Bok Hai. Bangkok: Chareonvit (vol.1 and vol.3); Bangkok: Mongkol (vol.2 and vol.4). (In Thai)

Phaen, Khun Chang Khun. 1970 (13th edition). Thonburi: Bannakarn press. (In Thai).

Pongsapich, Amara. 1997. "Feminism Theories and Praxis: Women's Social Movement in Thailand" in: Virada Somswasdi and Sally Theobald (eds.) Women, Gender Relations and Development in Thai Society. Chiang Mai: Ming Muang Navarat. pp.3-51.

Rabibhadana, Akin. 1980. "Thai Slum Women: A Case of Trok Tai" in: Suntaree A-Sawai and others (eds.) Thai Kadee Suksa. Bangkok: Amarin Printing Group. (in Thai)

"Rangrong" [Nidhi Aeusrivongs]. 1988. Laew Rao Koh Pruksa Kan. Bangkok: Ammarin Printing Group. (In Thai)

Reynolds, Craig J. 1977. “A Nineteenth Century Thai Buddhist Defense of Polygamy and Some Remarks on the Social History of Women in Thailand" in: Proceedings of Seventh IAHA Conference, vol.2. 22-26 August 1977, Chulalongkorn University, Bangkok. pp.927-970.

"Sasivimol" [Chakkapan Posayanond] 1976. Sasivimol Tob Panha. Bangkok: Duang Ta. (In Thai)

Sukpanich, Thavit. 1988. "Non-excessive Heart: The History of Husband and Wife(ves) 2" Ban Mai Ru Rooy. Vol.4, no.5. pp.84-93. (In Thai)

Wongyannava, Thanet. 1987. "The Logic of Repression: Foucault and Feminists" in: Thanet Wongyannava (ed.) Rattasart Sarn Special Edition: Philosophy and Thought. (In Thai) 